Jean-Luc Fellahi MD, *

Bruno Valtier $M D, *$

Alain Beauchet MD, $\dagger$

Jean-Pierre Bourdarias $\mathrm{MD}, \ddagger$

François Jardin $\mathrm{MD}^{*}$

\title{
Hemodynamic effects of medical antishock trousers during mechan- ical ventilation
}

Purpose: To compare the hemodynamic effects of medical antishock trousers (MAST) inflation in mechanically ventilated patients with normal and poor left ventricular function.

Methods: Twelve patients requiring respiratory support were divided into two groups according to baseline transesophageal echocardiography (TEE) measurements: normal left ventricular dimensions and fractional area of contraction (FAC $=6 \mid \pm 5 \%)(n=7)$ and dilated cardiomyopathy with reduced FAC $(2| \pm| \%)(n=5)$. All patients were studied when two successive levels of load (mild load by inflation of the leg compartment of MAST at $50 \mathrm{cmH}_{2} \mathrm{O}$ and high load by adding the abdominal compartment of MAST inflated at $30 \mathrm{cmH}_{2} \mathrm{O}$ ) were applied. Global left ventricular systolic function was assessed on the TEE transgastric short-axis view. End-systolic wall stress (ESWS) was used as an indicator of left ventricular afterload.

Results: Total respiratory, lung and chest wall compliances were reduced by $48 \%, 51 \%$ and $27 \%$ respectively at the high load level $(P<0.05)$. Whereas no hemodynamic changes occurred at mild load, the high load level produced an increase in left ventricular afterload as evidenced by concomitant increases in diastolic arterial blood pressure ( $66 \pm 6$ to $79 \pm 6 \mathrm{mmHg}, P<0.05)$ and ESWS $\left(69 \pm 12\right.$ to $\left.74 \pm 12 \mathrm{Kdyn} \cdot \mathrm{cm}^{-2} \cdot \mathrm{m}^{-2}, P<0.05\right)$. In patients with dilated cardiomyopathy, this increase in afterload impaired the left ventricular systolic function and end-systolic area increased $\left(19.0 \pm 2.5\right.$ to $\left.21.4 \pm 2.9 \mathrm{~cm}^{2} \cdot \mathrm{m}^{-2}, P<0.05\right)$ while FAC decreased $(22 \pm 2$ to 16 $\pm 2 \%, P<0.05)$. Left ventricular end-diastolic area remained unchanged during the study in both groups.

Conclusion: MAST inflation impairs respiratory mechanics and global left ventricular systolic function in cardiac patients without changes in left ventricular preload.

Objectif : Comparer les effets circulatoires du pantalon antichoc (PAC) chez des patients ventilés à fonction ventriculaire gauche (VG) normale et altérée.

Méthodes : Douze patients ventilés ont été répartis en deux groupes selon les données de l'échocardiographie transesophagienne (ETO) : dimensions VG et fraction de raccourcissement de surface (FRS) normales ( $n=7$ ) ou myocardiopathie dilatée ( $F R S=21 \pm 1 \%)(n=5)$. Deux niveaux de charge ont été appliqués : charge légère obtenue en gonflant les membres inférieurs du PAC à $50 \mathrm{mmHg}$ et charge élevée en ajoutant le compartiment abdominal gonflé à $30 \mathrm{mmHg}$. La performance globale VG a été mesurée par ETO et le calcu de la contrainte télésystolique (CSVG) utilisé pour l'appréciation de la postcharge.

Résultats : Les compliances respiratoire totale, pulmonaire et pariétale sont abaissées pour le niveau de charge élevé. Si le niveau de charge légère n'a pas entrainé de modifications hémodynamiques, la charge élevée a provoqué une augmentation de la post charge VG objectivée par l'augmentation de la pression artérielle diastolique (66 \pm 6 à $79 \pm 6 \mathrm{mmHg}, P<0,05)$ et de la CSVG $\left(69 \pm 12\right.$ à $\left.74 \pm 12 \mathrm{Kdyn}^{\circ} \mathrm{cm}^{-2} \cdot \mathrm{m}^{-2}, P<0,05\right)$. Chez les patients dilatés, cette élévation de postcharge s'est accompagnée d'une détérioration de la performance VG : augmentation de la surface télésystolique $V G\left(19,0 \pm 2,5\right.$ à $\left.21,4 \pm 2,9 \mathrm{~cm}^{-2} \cdot \mathrm{m}^{-2}, P<0,05\right)$ et diminution de la FRS (22 \pm 2 à $16 \pm 2 \%, P<0,05)$. Les dimensions diastoliques VG n'ont pas varié au cours de l'étude.

Conclusion : Le PAC altère la mécanique respiratoire et génère une élévation de postcharge VG qui détériore la fonction systolique globale chez les patients cardiaques sans modifier la précharge VG.

From the Medical Intensive Care Unit, * Biostatistics Department, $\nmid$ and the Department of Cardiology, $\ddagger$ Hôpital Ambroise Paré, University of Paris V, France.

Address correspondence to: Docteur Jean-Luc Fellahi, Département d'Anesthésie-Réanimation, C.H.P. Saint- Martin, 18 rue des Roquemonts, 14050 Caen Cedex, France. Phone: 33-2-31-43-31-20; Fax: 33-2-31-43-31-24.

Accepted for Publication February 3, 1999 
$M$

EDICAL antishock trousers (MAST) have been recommended for treatment of life-threatening hypovolemic hypotension and intraperitoneal or retroperitoneal hemorrhage. ${ }^{1,2}$ However, by an increase in abdominal pressure, MAST inflation can induce abrupt changes in transdiaphragmatic pressure and create a gradient between the external pressures surrounding the intrathoracic and extrathoracic vessels, leading to major changes in left ventricular preload and afterload. ${ }^{3}$ Critically-ill patients often require intermittent positive pressure ventilation which acts on transdiaphragmatic pressure and left ventricular load conditions. $^{3,4}$ The effects of MAST inflation in non cardiac patients undergoing mechanical ventilation have been elucidated after cardiac surgery. ${ }^{5}$ The central hemodynamic changes due to MAST inflation have also been studied in patients with chronic congestive heart failure breathing spontaneously. ${ }^{6}$ Whether global left ventricular performance improves or impairs during load challenge by means of MAST in mechanically ventilated patients with compromised cardiac function is however not known.

The aim of the present study was to compare the hemodynamic effects of a sudden increase in transdiaphragmatic pressure induced by means of MAST in mechanically ventilated patients with normal and poor left ventricular function.

\section{Methods \\ Patients}

Twelve critically-ill patients who required mechanical ventilation for an acute episode of respiratory failure were studied. Respiratory failure resulted from extensive bacterial pneumonia in one case, acute exacerbation of chronic obstructive pulmonary disease in six cases and cardiogenic pulmonary edema in five cases (Table I). Patients were divided into two groups according to the baseline left ventricular transesophageal echocardiographic measurements: group l ( $n=7$ ) with normal left ventricular dimensions and systolic function and group $2(n=5)$ with dilated cardiomyopathy and markedly reduced systolic function (Table III, baseline column). All patients with cardiogenic pulmonary edema had a history of cardiac dysfunction and were in group 2 . Conversely, no patient in group 1 had a history of acute or chronic left ventricular disease. The study was in accordance with the ethical regulations of our country (Huriet's law) and approved by the Comité Consultatif de Protection des Personnes dans la Recherche Biomédicale of Ambroise Paré Hospital. At the time of the study, the lungs of all patients were being ventilated in the controlled mode with a ventilator (7200 Series;
Puritan Bennett; Carlsbad, CA) that delivered at constant inspiratory flow rate and respiratory frequency of 12 cycles $\cdot \mathrm{min}^{-1}$ a tidal volume of $10 \mathrm{ml} \cdot \mathrm{kg}^{-1}$ body weight with an end-inspiratory pause of $0.4 \mathrm{sec}$ and zero end-expiratory pressure (ZEEP). Inspired oxygen concentration was maintained at $50 \%$. During the brief period of the study, the patients were sedated with 0.1 $\mathrm{mg} \cdot \mathrm{kg}^{-1} \cdot \mathrm{hr}^{-1}$ midazolam and $0.5 \mu \mathrm{g} \cdot \mathrm{kg}^{-1} \cdot \mathrm{hr}^{-1}$ sufentanil. No change in baseline therapy was carried out during the study period.

\section{Measurements}

Airway pressures were obtained from the ventilator. Using a side-port of the tracheal tube, airway pressures were also displayed on the $\mathrm{M}$-mode tracing to record the respiratory cycle during echocardiographic study. End-inspiratory (Ppli) and end-expiratory (Pple) pleural pressures were measured before transesophageal echocardiography (TEE) examination by using an esophageal balloon advanced through the nose into the esophagus $35-40 \mathrm{~cm}$ from the nares, inflated with $10 \mathrm{ml}$ air and allowed to deflate spontaneously, resulting in a residual volume of approximately $0.2 \mathrm{ml}$ air. Balloon placement was considered to be correct when the patient was briefly disconnected from the ventilator and a negative pleural pressure was recorded. Total respiratory compliance (CT) was computed as: $\mathrm{CT}=\mathrm{V}_{\mathrm{T}} /(\mathrm{Pi}-\mathrm{Pe})$ where $\mathrm{V}_{\mathrm{T}}$ was inspired tidal volume and $(\mathrm{Pi}-\mathrm{Pe})$ the difference between the end-inspiratory and end-expiratory airway pressure with a correction for intrinsic PEEP (measured with the end-expiratory occlusion hold of the ventilator) when present. Lung compliance (CL) was calculated

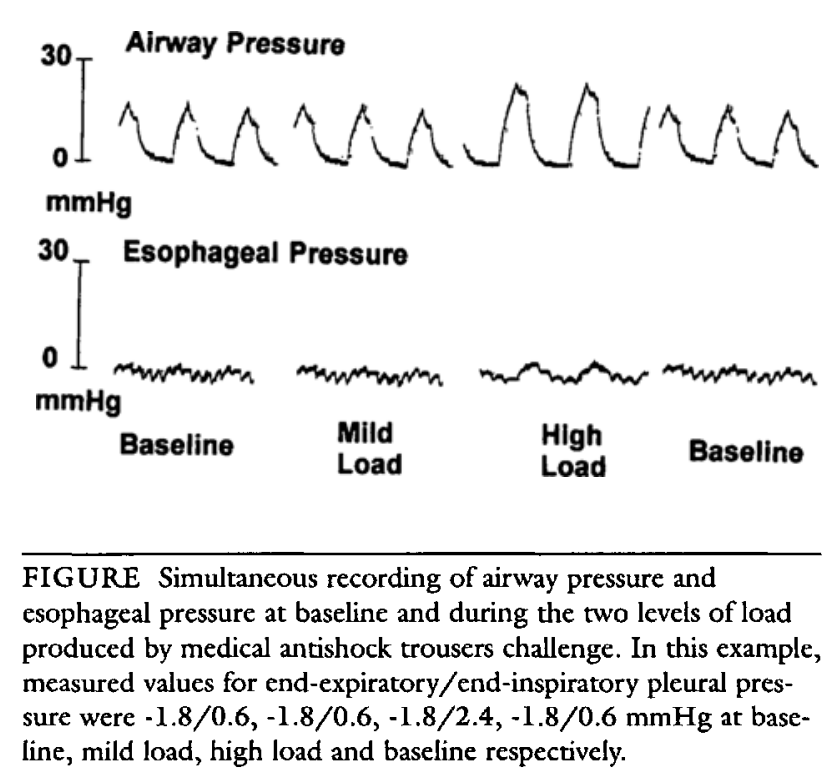


TABLE I Clinical data and outcome of patients in both groups. * COPD: chronic obstructive pulmonary disease, CPE: cardiogenic pulmonary edema, Dop: dopamine, Dob: dobutamine, NSurv: nonsurvivor, Surv: survivor.

\begin{tabular}{|c|c|c|c|c|c|}
\hline $\begin{array}{l}\text { Patient } \\
\text { (n) }\end{array}$ & $\begin{array}{l}\text { Age } \\
(y r)\end{array}$ & Sex & Diagnosis* & $\begin{array}{l}\text { Hemodynamic } \\
\text { therapy* }\end{array}$ & Outcome \\
\hline \multicolumn{6}{|l|}{ Group 1} \\
\hline 1 & 76 & $\mathbf{M}$ & COPD & - & NSurv \\
\hline 2 & 69 & $\mathbf{M}$ & COPD & - & NSurv \\
\hline 3 & 66 & $\mathbf{M}$ & COPD & - & NSurv \\
\hline 4 & 82 & $\mathbf{M}$ & COPD & $\cdot$ & NSurv \\
\hline 5 & 34 & $\mathbf{M}$ & Pneumonia & Dop $=5 \mu \mathrm{g} \cdot \mathrm{kg}^{-1} \cdot \mathrm{min}^{-1}$ & Surv \\
\hline 6 & 63 & M & COPD & - & Surv \\
\hline 7 & 61 & $\mathrm{~F}$ & COPD & - & Surv \\
\hline \multicolumn{6}{|c|}{ Group 2} \\
\hline 1 & 60 & $\mathbf{M}$ & $\mathrm{CPE}$ & Dob $=15 \mu \mathrm{g} \cdot \mathrm{kg}^{-1} \cdot \mathrm{min}^{-1}$ & NSurv \\
\hline 2 & 59 & $\mathbf{M}$ & CPE & Dob $=12 \mu \mathrm{g} \cdot \mathrm{kg}^{-1} \cdot \mathrm{min}^{-1}$ & Surv \\
\hline 3 & 61 & $\mathbf{M}$ & $\mathrm{CPE}$ & Dobu $=12 \mu \mathrm{g} \cdot \mathrm{kg}^{-1} \cdot \mathrm{min}^{-1}$ & NSurv \\
\hline 4 & 73 & F & CPE & & Surv \\
\hline 5 & 67 & M & CPE & $\mathrm{Dob}=6 \mu \mathrm{g} \cdot \mathrm{kg}^{-1} \cdot \mathrm{min}^{-1}$ & NSurv \\
\hline
\end{tabular}

TABLE II Respiratory data at baseline and changes during load challenge for the whole group ( $n=12$ ). Pple: end-expiratory pleural pressure, Ppli: end-inspiratory pleural pressure, CT: total respiratory compliance, $\mathrm{CL}$ : lung compliance, $\mathrm{CW}$ : chest wall compliance. Data are expressed as mean $\pm S E M,{ }^{*} P<0.05$ vs baseline.

\begin{tabular}{lllll}
\hline & Baseline & Mild load & High load & Baseline \\
\hline $\begin{array}{l}\text { Pple } \\
(\mathrm{mmHg})\end{array}$ & $-1.8 \pm 0.2$ & $-1.8 \pm 0.2$ & $-1.6 \pm 0.2$ & $-1.8 \pm 0.2$ \\
$\begin{array}{l}\text { Ppli } \\
(\mathrm{mmHg})\end{array}$ & $1.9 \pm 0.3$ & $2.0 \pm 0.3$ & $3.6 \pm 0.5^{\star}$ & $1.8 \pm 0.2$ \\
$\begin{array}{l}\mathrm{CT} \\
\left(\mathrm{ml} \cdot \mathrm{cmH} \mathrm{O}_{2} \mathrm{O}^{-1}\right)\end{array}$ & $44 \pm 7$ & $43 \pm 7$ & $24 \pm 3^{\star}$ & $45 \pm 7$ \\
$\begin{array}{l}\mathrm{CL} \\
\left(\mathrm{ml} \cdot \mathrm{cmH}_{2} \mathrm{O}^{-1}\right)\end{array}$ & $65 \pm 11$ & $63 \pm 10$ & $32 \pm 4^{*}$ & $69 \pm 10$ \\
$\begin{array}{l}\mathrm{CW} \\
\left(\mathrm{ml} \cdot \mathrm{cmH}_{2} \mathrm{O}^{-1}\right)\end{array}$ & $126 \pm 12$ & $129 \pm 14$ & $90 \pm 7^{\star}$ & $137 \pm 14$ \\
\hline
\end{tabular}

by dividing $\mathrm{V}_{\mathrm{T}}$ by end-inspiratory minus end-expiratory transpulmonary pressure (airway pressure minus pleural pressure) and chest wall compliance (CW) by dividing $V_{T}$ by end-inspiratory minus end-expiratory transthoracic pressure (pleural pressure minus atmospheric pressure). ${ }^{7}$

Systemic arterial blood pressure was measured via an indwelling radial catheter with a transducer (Transpac; Abbott Laboratories; North Chicago, Ill) positioned at the midaxillary line, with atmospheric pressure as a zero reference. Transmural systolic blood pressure $\left(S B P_{\mathrm{tm}}\right)$, defined as the peak arterial pressure minus pleural pressure, was used to approximate endsystolic pressure for noninvasive left ventricular merid- ional end-systolic wall stress (ESWS) calculation. ${ }^{8}$ Heart rate was obtained from the ECG.

Echocardiographic measurements were performed by a single trained investigator (HP 77020A; HewlettPackard; Andover, MA). A transesophageal $5 \mathrm{MHZ}$ single plane probe was positioned to obtain a shortaxis cross-sectional view of the left ventricle at the midpapillary muscle level. Echocardiographic images were recorded during the protocol and reviewed in a blinded fashion for single frame, stop-motion analysis. The end-diastolic frame was selected at the peak of the $\mathrm{R}$ wave on simultaneous ECG recording and the endsystolic frame was defined as the smallest ventricular dimension during the last half of the $T$ wave. Using a microcomputer interfaced with the videotape player, end-expiratory stop-motion frames at end-diastole and end-systole were displayed on the microcomputer screen to digitize the endocardial outlines of the left ventricle. End-diastolic (EDA) and end-systolic (ESA) areas were automatically processed. The stroke area (SA) was calculated as EDA-ESA and the fractional area of contraction (FAC) was calculated as SA/EDA. FAC provided global assessment of left ventricular systolic performance as the net result of the integration of cardiac inotropic state and loading conditions. Left ventricular end-systolic wall thickness (WT) was measured by the leading edge-to-leading edge technique via $\mathrm{M}$-mode recording. ESWS was calculated using Reichek's formula: ${ }^{8}$

\section{ESWS=0.334(SBPtmxESD)/WT $(1+W T / E S D)$}

where ESD was left ventricular end-systolic diameter.

To exclude possible changes in left ventricular shape during the study, an average ESD was computed from the measured ESA. The ESWS provided a reliable indication of left ventricular afterload by reflecting the combined effects of peripheral loading conditions and intrinsic cardiac properties. ${ }^{9}$

\section{Protocol}

After completion of a baseline set of measurements for each patient, a mild lower body positive pressure by means of MAST inflated to $50 \mathrm{cmH}_{2} \mathrm{O}$ in the leg compartment was applied for five minutes to obtain the first step of load (mild load) and measurements were repeated. Then, the load was increased further by adding the abdominal compartment of the MAST inflated to $30 \mathrm{cmH}_{2} \mathrm{O}$ while holding the leg compartment at the same inflation pressure and measurements were repeated after five minutes, providing the high lower body positive pressure level (high load). Finally, MAST was removed and a second set of baseline measurements was obtained. 
TABLE III Global hemodynamic parameters and echocardiographic data at baseline and changes during load challenge for both groups of patients. HR (b. $\left.\mathrm{min}^{-1}\right)$ : heart rate, SBP (mmHg): systolic blood pressure, DBP $(\mathrm{mmHg})$ : diastolic blood pressure, EDA $\left(\mathrm{cm}^{2} \cdot \mathrm{m}^{-2}\right)$ : end-diastolic area, ESA $\left(\mathrm{cm}^{2} \cdot \mathrm{m}^{-2}\right)$ : end-systolic area, $\mathrm{SA}\left(\mathrm{cm}^{2} \cdot \mathrm{m}^{-2}\right)$ : stroke area, FAC (\%): fractional area of contraction, ESWS $\left(\mathrm{Kdyn} \cdot \mathrm{cm}^{-2} \cdot \mathrm{m}^{-2}\right): \mathrm{end}^{-}$ systolic wall stress, NS: non significant. Data are expressed as mean $\pm S E M, * P<0.05$ vs baseline.

\begin{tabular}{|c|c|c|c|c|c|}
\hline & Baseline & Mild load & High load & Baseline & $\begin{array}{l}\text { Difference between groups, } \\
P \text { palue }\end{array}$ \\
\hline \multicolumn{6}{|l|}{ HR } \\
\hline Group 1 & $105 \pm 7$ & $104 \pm 7$ & $103 \pm 7$ & $104 \pm 7$ & \multirow[t]{2}{*}{ NS } \\
\hline Group 2 & $103 \pm 10$ & $104 \pm 10$ & $103 \pm 10$ & $105 \pm 10$ & \\
\hline \multicolumn{6}{|l|}{ SBP } \\
\hline Group 1 & $128 \pm 5$ & $135 \pm 5$ & $147 \pm 5^{*}$ & $123 \pm 5$ & \multirow[t]{2}{*}{$<0.05$} \\
\hline Group 2 & $129 \pm 9$ & $132 \pm 9$ & $138 \pm 9$ & $129 \pm 9$ & \\
\hline \multicolumn{6}{|l|}{ DBP } \\
\hline Group 1 & $70 \pm 9$ & $74 \pm 9$ & $84 \pm 9^{*}$ & $68 \pm 9$ & \multirow[t]{2}{*}{ NS } \\
\hline Group 2 & $64 \pm 4$ & $67 \pm 4$ & $72 \pm 4^{\star}$ & $61 \pm 4$ & \\
\hline \multicolumn{6}{|l|}{ EDA } \\
\hline Group 1 & $10.3 \pm 1.1$ & $10.7 \pm 1.1$ & $9.9 \pm 1.2$ & $10.0 \pm 1.2$ & \multirow[t]{2}{*}{ NS } \\
\hline Group 2 & $24.2 \pm 3.2$ & $25.6 \pm 3.5$ & $25.6 \pm 3.5$ & $24.2 \pm 3.2$ & \\
\hline \multicolumn{6}{|l|}{ ESA } \\
\hline Group I & $3.6 \pm 0.4$ & $3.9 \pm 0.4$ & $3.9 \pm 0.5$ & $3.6 \pm 0.4$ & \multirow[t]{2}{*}{$<0.05$} \\
\hline $\begin{array}{l}\text { Group } 2 \\
\text { SA }\end{array}$ & \multicolumn{4}{|c|}{ SA } & \\
\hline Group 1 & $6.7 \pm 1.0$ & $6.9 \pm 1.0$ & $6.0 \pm 1.0$ & $6.4 \pm 1.1$ & \multirow[t]{3}{*}{$<0.05$} \\
\hline Group 2 & $5.2 \pm 0.7$ & $5.8 \pm 1.2$ & $4.2 \pm 0.9^{*}$ & $5.2 \pm 0.8$ & \\
\hline \multicolumn{5}{|l|}{ FAC } & \\
\hline Group 1 & $63 \pm 5$ & $62 \pm 5$ & $59 \pm 5$ & $62 \pm 5$ & \multirow[t]{2}{*}{$<0.05$} \\
\hline Group 2 & $22 \pm 2$ & $22 \pm 2$ & $16 \pm 2^{*}$ & $22 \pm 2$ & \\
\hline \multicolumn{6}{|l|}{ ESWS } \\
\hline Group 1 & $33 \pm 4$ & $37 \pm 4$ & $39 \pm 4^{\star}$ & $32 \pm 4$ & \multirow[t]{2}{*}{ NS } \\
\hline Group 2 & $93 \pm 14$ & $97 \pm 4$ & $106 \pm 14^{*}$ & $89 \pm 14$ & \\
\hline
\end{tabular}

\section{Statistical analysis}

Statistical analysis was performed using statistical software (Statgraphics version 5.0; Uniware; Paris, France). Data are expressed as mean \pm SEM. Comparisons of means at each level of load (mild load and high load) with the average of baseline measurements within and between groups were performed using a two-way analysis of variance for repeated measurements, completed in case of significance by multiple comparisons tests using the contrast method. A test giving a $P$ value $<0.05$ was considered statistically significant.

\section{Results}

Clinical data and outcome in both groups of patients are indicated in Table I. Respiratory data for the whole group are presented in Table II. The Pple did not change during the study, whereas Ppli was increased by inflation of the abdominal compartment of the MAST (high load). Furthermore, at the high load level, total respiratory, lung and chest wall compliances were reduced by $48 \%, 51 \%$ and $27 \%$ respectively, $P<0.05$. An example of simultaneous recording of airway pressure and esophageal pressure when tidal volume was kept constant is shown in the
Figure. While end-expiratory esophageal pressure remained unchanged throughout the protocol period, both end-inspiratory airway and esophageal pressures were increased at high load and transpulmonary and transthoracic pressures were also increased.

Baseline left ventricular two-dimensional echocardiographic data (short-axis view) in both groups of patients are indicated in Table III (baseline column). Whereas patients in group 1 had left ventricular dimensions and FAC in the normal range, patients in group 2 had a dilated left ventricle with reduced FAC. The hemodynamic effects of the two successive steps of load (mild load and high load as defined earlier) for the two groups of patients are indicated in Table III. Heart rate remained unchanged during the study. Mild load produced a small non significant increase in arterial blood pressure in both groups. Applying the high load altered arterial blood pressure: systolic blood pressure was increased in group 1 and unchanged in group 2 and diastolic blood pressure was increased in both groups. No change in TEE data was found at the mild load level in both groups. At the high load level, the left ventricular dimensions and FAC were not affected in group 1 whereas an increase 
in ESA was associated with impairment in SA and FAC in group 2 patients. In addition, calculated ESWS was increased at the high load level in both groups of patients $(P<0.05)$.

\section{Discussion}

Inflation of MAST produces a gradient between the external pressures surrounding the intrathoracic and extrathoracic vessels because it increases the external pressure surrounding the extrathoracic vessels without changing the external pressure acting on the intrathoracic vessels (i.e. pleural pressure). Such an assumption assumes that the increase in abdominal pressure produced by MAST in mechanically ventilated patients is not transmitted to the thoracic cavity. Indeed, no change in end-expiratory pleural pressure was found in the present study during the abdominal compression by MAST at high load. Conversely, when the abdominal compression was combined with lung inflation, a clear increase in end-inspiratory pleural pressure was observed, resulting from the impairment in chest wall compliance. ${ }^{7}$ These clinical findings observed with MAST confirm previous published experimental data. ${ }^{10}$

The pressure gradient between the abdominal and thoracic compartments is responsible for major circulatory changes due to both an increase in left ventricular preload and afterload. ${ }^{3}$ Nonetheless, it acts in a complex way on left ventricular preload and in a simple way on left ventricular afterload. The effects of the pressure gradient on left ventricular preload involve systemic venous return and cardiac distensibility. Theoretically, venous return increases when the gradient is increased and decreases when the gradient is decreased or reversed. However, it depends on the intravascular volume of the abdominal venous compartment, ${ }^{11}$ so that the resultant hemodynamic effect is equivocal. ${ }^{12}$ Moreover, the increase in venous return may increase the central blood volume (i.e. the left ventricular filling reserve) without change in left ventricular preload if the left ventricular distensibility is simultaneously decreased. In the present study, we did not find any variation in end-diastolic dimensions during the load challenge by MAST, neither in patients with normal left ventricular function nor in patients with compromised cardiac function. Such a lack of effect on left ventricular preload was expected in group 1 since a normally filled healthy left ventricle does not significantly dilate in response to an increase in venous return because of the pericardial constraint. The pressure-volume relationship becomes vertical close to the optimal filling pressure. ${ }^{13}$ The lack of effect was also expected in group 2 for the same reason. Indeed, in chronically dilated cardiac patients, the left ventricle acts at end-diastole on the vertical part of its pressure-volume relationship and a substantial increase in end-diastolic pressure may well occur without any change in end-diastolic volume. Conversely, MAST has been found to be an efficient means to restore the left ventricular preload in settings where it was abnormally reduced, as during PEEP ventilation. ${ }^{14,15}$

The effects of the pressure gradient on left ventricular afterload have been well documented in the past by experimental and clinical studies where a negative pleural pressure increased afterload ${ }^{16,17}$ and positive pleural pressure decreased afterload ${ }^{18,19}$ of the left ventricle. Furthermore, the increase in intra-abdominal pressure induced by intraperitoneal gas insufflation has been found, both experimentally $y^{10,12}$ and clinical$\mathrm{ly}^{20}$ to increase cardiac afterload. Thus, the MASTrelated pressure gradient increase should induce an acute increase in left ventricular afterload. As expected, a documented rise in ESWS (a more reliable index of left ventricular afterload than systemic vascular resistance index) ${ }^{9}$ was observed in both groups of patients when the MAST abdominal area was inflated. The tolerance was apparently good in patients with normal cardiac function and no significant impairment in global left ventricular systolic performance was evidenced. At the other extreme, hemodynamic deterioration was shown in patients with compromised cardiac function as FAC was decreased by $27 \%$. The amount of increase in left ventricular afterload during MAST inflation may be estimated by measuring the increase in diastolic arterial blood pressure. At the high load level, the end-expiratory increase in diastolic arterial blood pressure was $13 \mathrm{mmHg}$ on average. Changes of greater magnitude when referenced to pleural pressure have been previously documented in dyspneic patients with an increase of $14 \mathrm{mmHg}$ during spontaneous inspiration. ${ }^{21}$

In summary, no increase in left ventricular preload, as assessed with TEE, was found in the present study when the MAST was inflated (including the abdominal area) in normovolemic patients with normal and poor left ventricular function undergoing mechanical ventilation. Conversely, an increase in afterload along with a decrease in systolic cardiac function was well seen in patients with impaired left ventricular function. In clinical practice, the hemodynamic adverse effects of MAST must be considered in such cardiac patients. Other studies conducted in patients with compromised cardiac function are needed to evaluate further the hemodynamic consequences of an abrupt increase in transdiaphragmatic pressure, as it occurs during weaning from mechanical ventilation or surgical laparoscopic procedures. 


\section{References}

1 Cutler BS, Dagget WM. Application of the "G-suit" to the control of hemorrhage in massive trauma. Ann Surg 1971; 173: 511-4.

2 Pelligra $R$, Sandberg EC. Control of intractable abdominal bleeding by external counterpression. JAMA 1979; 241: 708-13.

3 Permutt $S$. Circulatory effects of weaning from mechanical ventilation: the importance of transdiaphragmatic pressure (Editorial). Anesthesiology 1988; 69: 157-60.

4 Pinsky $M R$. The hemodynamic consequences of mechanical ventilation: an evolving story. Intensive Care Med 1997; 23: 493-503.

5 Burchard KW, Slotman GJ, Jed E, Singh AK, Gann DS, Positive pressure respirations and pneumatic antishock garment application - hemodynamic response. J Trauma $1985 ; 25: 83-9$.

6 Bain RI, Tan LB, Murray RG, Davies MK, Littler WA. Central hemodynamic changes during lower body positive pressure in patients with congestive cardiac failure. Cardiovasc Res 1989; 23: 833-7.

7 Jardin F, Genevray B, Brun-Ney D, et al. Influence of lung and chest wall compliances on transmission of airway pressure to the pleural space in critically ill patients. Chest $1985 ; 88$ : 653-8.

8 Reichek N, Wilson J, St John Sutton M, Plappert TA, Goldberg S, Hirshfeld JW. Noninvasive determination of left ventricular end-systolic stress: validation of the method and inirial application. Circulation 1982; 65: 99-108.

9 Lang RM, Borow KM, Neumann A, Janzen $D$. Systemic vascular resistance: an unreliable index of left ventricular afterload. Circulation 1986; 74: 1114-23.

10 Ivankovich AD, Miletich DJ, Albrecht RF, Heyman HJ, Bonnet $R F$. Cardiovascular effects of intraperitoneal insufflation with carbon dioxide and nitrous oxide in the dog. Anesthesiology 1975; 42: 281-7.

11 Takata M, Wise RA, Robotham JL. Effects of abdominal pressure on venous return: abdominal vascular zone conditions. J Appl Physiol 1990; 69: 1961-72.

12 Diamant $M$, Benumof JL, Saidman LJ. Hemodynamics of increased intra-abdominal pressure: interaction with hypovolemia and halothane anesthesia. Anesthesiology 1978; 48: 23-7.

13 Holt JP. The normal pericardium. Am J Cardiol 1970; 26: 455-65.

14 Payen DM, Carli PA, Brun-Buisson CJL, et al. Lower body positive pressure vs. dopamine during PEEP in humans. J Appl Physiol 1985; 58: 77-82.

15 Payen DM, Brun-Buisson CJL, Carli PA, et al. Hemodynamics, gas exchange and hormonal consequences of LBPP during PEEP ventilation. J Appl Physiol 1987; 62: 61-70.
16 Buda AJ, Pinsky MR, Ingels NB Jr, Daughters GT II, Stinson EB, Alderman EL. Effect of intrathoracic pressure on left ventricular performance. $N$ Engl J Med 1979; 301: 453-9.

17 Scharf SM, Bianco JA, Tow DE, Brown R. The effects of large negative intrathoracic pressure on left ventricular function in patients with coronary artery disease. Circulation 1981; 63: 871-5.

18 Pinsky MR, Summer WR, Wise RA, Permutt $S$, Bromberger-Barnea $B$. Augmentation of cardiac function by elevation of intrathoracic pressure. J Appl Physiol 1983; 54: 950-5.

19 Pinsky MR, Matuschak GM, Klain M. Determinants of cardiac augmentation by elevations in intrathoracic pressure. J Appl Physiol 1985; 58: 1189-98.

20 Safran D, Sgambati S, Orlando R III. Laparoscopy in high-risk cardiac patients. Surg Gynecol Obstet 1993; 176: 548-54.

21 Jardin $F$, Farcot J-C, Boisante L, Prost J-F, Gueret $P$, Bourdarias J-P. Mechanism of paradoxical pulse in bronchial asthma. Circulation 1982; 66: 887-94. 